Boise State University

ScholarWorks

Computer Science Faculty Publications and Presentations

Department of Computer Science

6-2021

\title{
Using Service-Learning in Graduate Curriculum to Address Teenagers' Vulnerability to Web Misinformation
}

Francesca Spezzano

Boise State University

Publication Information

Spezzano, Francesca. (2021). "Using Service-Learning in Graduate Curriculum to Address Teenagers' Vulnerability to Web Misinformation". ITiCSE '21: Proceedings of the 26th ACM Conference on Innovation and Technology in Computer Science Education, 2, 637-638. https://doi.org/10.1145/3456565.3460039

This document was originally published in ITiCSE '21: Proceedings of the 26th ACM Conference on Innovation and Technology in Computer Science Education by Association for Computing Machinery. Copyright restrictions may apply. https://doi.org/10.1145/3456565.3460039 


\title{
Using Service-Learning in Graduate Curriculum to Address Teenagers' Vulnerability to Web Misinformation
}

\author{
Francesca Spezzano \\ Computer Science Department \\ Boise State University (USA) \\ francescaspezzano@boisestate.edu
}

\begin{abstract}
We report on how we implemented service-learning (S-L) in a CS graduate class to improve student understanding of the class materials and provide a service to the community, i.e., addressing teenagers' vulnerability to Web misinformation. We show how SL benefits CS students in their course theory understanding and personal skills development, while teenagers' news media literacy and misinformation detection accuracy were positively impacted.
\end{abstract}

\section{CCS CONCEPTS}

- Applied computing $\rightarrow$ Education.

\section{KEYWORDS}

Service-learning, misinformation, news media literacy

ACM Reference Format:

Francesca Spezzano. 2021. Using Service-Learning in Graduate Curriculum to Address Teenagers' Vulnerability to Web Misinformation. In 26th ACM Conference on Innovation and Technology in Computer Science Education V. 2 (ITiCSE 2021), June 26-fuly 1, 2021, Virtual Event, Germany. ACM, New York, NY, USA, 2 pages. https://doi.org/10.1145/3456565.3460039

\section{INTRODUCTION}

Service-learning (S-L) is a teaching strategy that integrates course content with relevant community service. Lectures, assignments, and class discussions prompt students to reflect critically on service in order to increase understanding of course content, gain a broader appreciation of the discipline, enhance their sense of civic responsibility, and become more active as local, national, and global citizens. ${ }^{1}$ Service-Learning in STEM provides many benefits to college students, including increased student learning [6], and offers both improved critical thinking and civic aptitude [2,3]. Servicelearning is particularly beneficial in attracting and retaining women and other underrepresented students in computing [1].

In this paper, we describe our experience in introducing servicelearning into a Social Media Mining class to develop an active learning environment where students will better understand class concepts and address the community issue of teens' lack of awareness regarding Web misinformation.

\footnotetext{
${ }^{1}$ National and Community Service Trust Act, 1993.

Permission to make digital or hard copies of part or all of this work for personal or classroom use is granted without fee provided that copies are not made or distributed for profit or commercial advantage and that copies bear this notice and the full citation on the first page. Copyrights for third-party components of this work must be honored For all other uses, contact the owner/author(s).

ITiCSE 2021, June 26-fuly 1, 2021, Virtual Event, Germany

(C) 2021 Copyright held by the owner/author(s).

ACM ISBN 978-1-4503-8397-4/21/06.

https://doi.org/10.1145/3456565.3460039
}

The community need. The majority of teenagers are unable to assess the credibility of Web information. According to a Stanford University study of 7,804 students from middle school to college, more than $80 \%$ of middle-schoolers could not distinguish between an advertisement and a real news story on a website. And nearly $40 \%$ of high-school students believed fake news as real one based only on the headline and picture [7]. To address this issue, many studies support news media literacy as one of the most powerful tools to fight fake news [4], especially for younger generations.

News media literacy. We adopted the $5 \mathrm{Cs}$ model proposed in [5] that defines News Literacy (NL) as "knowledge of the personal and social processes by which news is produced, distributed, and consumed, and skills that allow users some control over these processes" and adapted it to the social media context. The $5 \mathrm{Cs}$ refer to the following five knowledge and skill domains that comprise NL: context, creation, content, circulation, and consumption. To measure the NL level of an individual, we collaborated with Dr. Ashley, one of the authors of [5], who developed five multiple-choice questions, each one testing knowledge in one of the 5Cs domains. We then defined the NL level as the percentage of corrected answers to these five questions.

\section{INTEGRATING SERVICE-LEARNING INTO SOCIAL MEDIA MINING CLASS}

Social Media Mining (SMM) is a graduate class offered by the author at Boise State University that introduces the basic concepts and presents the principal algorithms to analyze social networks and mine social media data. One of the applications presented in the fall ' 20 offering of the class was misinformation detection and mitigation on the Web. The course included a final project requiring students to use machine learning to classify real and fake news. Also, the SMM class adopted a fully integrated S-L model, i.e., the service experience is used as the basis for papers, class presentations, discussion, and other assignments, and instructors deliberately link the academic content with the service experience and the community issue. More specifically, through the S-L component of the class, SMM students were asked to: (1) research the issue and its impacts on the target population; (2) design and deliver an interactive presentation to high school students that highlights the threat of misinformation, the importance of CS in helping society overcome misinformation, and why they are choosing CS for their careers; (3) reflect on and communicate their learning through final reflections. Regarding the presentation design (item (2) above), students received guidelines to ensure content uniformity. Specifically, we asked them to define misinformation and provide examples of its different types, explain why misinformation is dangerous, provide an example of truthful vs. fake news and explain which 
Table 1: SMM student reflections about their S-L experience.

\begin{tabular}{|c|c|}
\hline Question & Answers \\
\hline $\begin{array}{l}\text { How does the service experience relate to class material? } \\
\text { What aspects of your learning may be due to your service experience? }\end{array}$ & $\begin{array}{l}\text { theoretical knowledge learned in class about social network, misinformation, fake news; practical } \\
\text { implementation via service-learning; application in a real-world situation. } \\
\text { public reactions on misinformation and distinguishing fake news; communication and information } \\
\text { sharing with non-technical people; solidified ideas and concepts learned in class; learned more about } \\
\text { media literacy; better understanding of fake news and how they spread. }\end{array}$ \\
\hline What do you perceive as the underlying issue, and why does it exist? & $\begin{array}{l}\text { spread awareness about misinformation and how not to spread it; to introduce students about } \\
\text { computer science career path; teaching someone is one of the best ways to learn it yourself; } \\
\text { responsibility towards society. } \\
\text { inability to discern veracity of news due to lack of knowledge, awareness, and skills; lack of news media } \\
\text { literacy; information overload; time consuming to fact-check; high exposure of students/teenagers to } \\
\text { information in social media; carelessness of media about policies and removing illegitimate content; } \\
\text { inherent political and social bias; economic incentives; not enough school education on misinformation. }\end{array}$ \\
\hline $\begin{array}{l}\text { What personal qualities have you developed through service-learning? } \\
\text { How will these qualities help you in the future? }\end{array}$ & $\begin{array}{l}\text { communication; teamwork; patience; leadership; compassion; creative thinking; tolerance; } \\
\text { sense of responsibility. } \\
\text { time management; team player. }\end{array}$ \\
\hline
\end{tabular}

characteristics make the examples truthful or fake, introduce the NL 5Cs model, provide final tips to spot misinformation on the Web, and briefly describe their class project about detecting fake news.

All the above-described activities have been spread out in different assignments through the semester together with other regular homework assignments. All but the NL model was part of the regular coursework. Dr. Ashley delivered a guest lecture about NL. Students worked in teams for all service-learning-related assignments and the class project. Instruments used in the class and sample student deliverables will be shown during the paper presentation.

We collaborated with Boise High School, and five groups of SMM students delivered their presentations to five sections of the AP CS Principles class (one group per section). Because of the current pandemic, the presentation was delivered online and synchronously, allowing interaction between high school and university students.

\section{ASSESSMENT}

We evaluated our service-learning-based activity on the graduate students who attended the SMM class and delivered the presentation ( $\mathrm{n}=16$ students) and the high school students who attended their presentation. We reached out to 70 Boise High students across all five sections of AP CS Principles. We investigated two research questions: (RQ1) did S-L benefit SMM students in their course theory understanding and personal skills development? (RQ2) Did we improve news media literacy and credibility accuracy in high school students through SMM students' S-L?

SMM students learning evaluation (RQ1). To answer RQ1, we asked SMM students to reflect on their service-learning experience at the end of the class and after they delivered the presentation to the Boise High students. Reflection was fostered by asking students to answer the three questions reported in Table 1, which also show SMM students' most common answers. Here, we see how students were able to link several concepts studied in class to their real-world S-L experience (including the need for their service) and recognize how communicating them with a non-technical audience helped them solidify concepts. Moreover, they recognized how S-L helped them develop several personal skills, including communication, teamwork and patience, leadership, creative thinking, and a sense of responsibility.

High school students learning evaluation (RQ2). To evaluate high school students' learning on Web misinformation before and after SMM students' presentation, we asked them to answer a pre- and post-survey. Both surveys contained demographic related questions, the five questions designed to measure NL level, and six questions randomly selected from a pool of 24 questions $^{2}$ asking students to assess the credibility (real or fake) of a news item presented as headline and accompanying image. Students received a $\$ 15$ gift card upon completion of both the pre- and post- survey. Out of the 70 high school students, $n=54$ answered the pre-survey and $n=25$ also followed up with the post-survey. Results assessing RQ2 are reported here below:

\begin{tabular}{r||c|c} 
& pre-survey & post-survey \\
\hline \hline News literacy level & $63.7 \%$ & $70.4 \%$ \\
News credibility accuracy & $59.6 \%$ & $63.1 \%$ \\
\hline \hline
\end{tabular}

As we can see, we measured an improvement in both news media literacy level (from $63.7 \%$ to $70.4 \%$ ) and news credibility accuracy (from $59.6 \%$ to $63.1 \%$ ). While these results are still preliminary and not conclusive because of the small sample size who answered the pre- and post- surveys, they still suggest that exposing teenagers to the Web misinformation problem may have a positive impact in helping them to fight their vulnerability.

Acknowledgements. This work has been sponsored by NSF award \#1943370. We thank Dr. Seth Ashley (Department of Communication and Media at Boise State University) and Ms. Lindsay Davis (Boise High School) for collaborating on this project.

\section{REFERENCES}

[1] Teresa Dahlberg, Tiffany Barnes, Kim Buch, and Karen Bean. 2010. Applying service learning to computer science: attracting and engaging under-represented students. Computer Science Education 20, 3 (2010), 169-180.

[2] Chantal Levesque-Bristol, Timothy D Knapp, and Bradley J Fisher. 2011. The effectiveness of service-learning: It's not always what you think. Journal of Experiential Education 33, 3 (2011), 208-224.

[3] Lenore M Molee, Mary E Henry, Valerie I Sessa, and Erin R McKinney-Prupis. 2011. Assessing learning in service-learning courses through critical reflection. fournal of Experiential Education 33, 3 (2011), 239-257.

[4] Pen America. 2018. Faking News: Fraudulent News and the Fight for Truth. https://pen.org/faking-news/.

[5] Emily K Vraga, Melissa Tully, Adam Maksl, Stephanie Craft, and Seth Ashley. 2021. Theorizing news literacy behaviors. Communication Theory 31, 1 (2021), 1-21.

[6] Jami L Warren. 2012. Does service-learning increase student learning?: A metaanalysis. Michigan journal of community service learning 18, 2 (2012), 56-61.

[7] Sam Wineburg, Sarah McGrew, Joel Breakstone, and Teresa Ortega. 2016. Evaluating information: The cornerstone of civic online reasoning. Stanford Digital Repository. Retrieved January 8 (2016), 2018.

${ }^{2}$ These questions were selected from the politifact. com fact-checking website. For the same student, pre- and post- survey contained different questions. 